\title{
COMPILATION OF AN ECONOMETRIC HUMAN RESOURCE EFFICIENCY MODEL FOR PROJECT MANAGEMENT BEST PRACTICES
}

\author{
G VAN ZYL \\ gvz@eb.rau.ac.za \\ Department of Economics \\ University of Johannesburg \\ P VENIER \\ Venier@capetown.gov.za \\ The Department of Public Enterprises
}

\begin{abstract}
The aim of the paper is to introduce a human resource efficiency model in order to rank the most important human resource driving forces for project management best practices. The results of the model will demonstrate how the human resource component of project management acts as the primary function to enhance organisational performance, codified through improved logical end-state programmes, work ethics and process contributions. Given the hypothesis that project management best practices involve significant human resource and organisational changes, one would reasonably expect this process to influence and resonate throughout all the dimensions of an organisation.
\end{abstract}

Key words

Project management, efficiency, Econometric modelling

The aim of the paper is to introduce a human resource efficiency model in order to rank the most important human resource driving forces for project management best practices. The Department of Public Enterprises (hereafter referred to as the DPE) was used as a case study.

"Project management is in essence a human resource exercise and in a project-driven organisation it is becoming more and more visible and more and more money is being spent to support the discipline of project management. Like you, top management is going to start asking where this money is going and what they are getting out of it. We'd better be ready to answer." (Knutson, 2001, p. 456).

There is an assumption that the average citizen and shareholder expect to receive more in terms of the delivery of services and products for less money. This desirable outcome can only be achieved if the organisation work more efficiently and provide more effective services and products at a lower cost to its citizens.

To be able to deliver these improved services and products at lower cost, it is required that an organisation implement its integrated strategic development plan and the programmes attached thereto through a clearly defined project-management approach.

The course of action to establish a best practise projectmanagement methodology, process and procedure can be supported by a corporate central project-management office, headed by a professional project manager with sufficient authority within the department.

\section{Literature study}

A thorough literature study was performed in order to identify all the human resource driving forces for optimal project management that could be included as independent variables in the econometric model.

The major part of the literature that deals with the human resource component of optimal project management relates to the methodology of project management, effective learning and authority structures and the adequacy of human resources. The next few paragraphs deal with these important aspects of the human resource component of optimal project management.
Portfolios and programmes

The methodology of project management encompasses in main portfolios and programmes.

A portfolio is a compilation of projects within a department, related to a specified time-frame that needs to be co-managed, whether they are interconnected or autonomous. A rigorous project-priority system should be used to select which projects will be budgeted for and staffed in the department (Gray and Larson, 2003, p. 33). Three different kinds of projects that can be found in a department's portfolio are i) compliance and priority/emergency projects (must do), ii) operational projects (daily, routine projects needed to support current operations) and iii) strategic projects (creation of new assets, recapitalisation of parastatals).

Gray and Larson (2003, p. 43) also state that, using the portfolio management system in a department, projects are assessed within the context of existing projects. Two major inputs are required from management in this process. Firstly, senior leadership must provide guidance in establishing and defining selection criteria of projects that strongly align with the current departmental strategies. Secondly, senior management must annually decide how they wish to bring equilibrium to available departmental resources among the different types of projects.

According to Knutson (2001, p. 188) portfolio management restores manageability by providing a department with an answering evaluation method that can be applied objectively to each proposed project. Every project must be properly scoped, planned and managed for the department to implement successful portfolio management. Projects are major investments for most departments. Investments must be managed on a portfolio-basis (Archibald, 2003, p. 11).

Multiple projects can form a programme with a single business objective. It is feasible for all the individual projects, many of which interface with each other, to contribute to this programme. These related projects could be managed with relative ease in the project-management environment. However, if the project manager has to manage multiple unrelated projects, the effort becomes much more complicated and difficult. 
Factors making the management of multiple projects different to that of single projects, even though they may be obvious, need to be spelled out. With single projects one has one single objective to reach, one to do list, a focussed work-breakdown structure and a defined resource pool to draw from. In a multiple-project environment one has a totally different situation where each project has its own objective and where resources come from all over and require different functions in the department.

A general problem experienced with traditional project management, according to Frame $(2002$, p. 7$)$, is the fact that it can be focussed only on the product life cycle from starting the project to completion thereof. This does not take into consideration customer satisfaction and ignores the life after the project-realisation of benefits.

The basic criteria for projects that lend themselves to project management (Knutson, 2001, p. 7) are i) a well-defined deliverable that is neither vague nor ambiguous, documented in a scope definition or statement of work ii) a collection of activities that will culminate in the end product iii) activities with starting and finishing points and iv) activities that can be scheduled.

\section{Project team and project-management office}

Effective learning and authority structures and the adequacy of human resources in optimal project management can best be described in the manner in which project teams operate and how well the project- management office is staffed.

A project team is often a frequently variable body of people from different levels of the department, many of whom may never meet each other. Departmental team work describes this type of collaboration. Breiner et al (1990, p. 7) continues to define the project team as: "All those individuals who have a significant contribution to make to the successful achievement of the project through one or more of i) their technical or specialist expertise ii) their sponsorship, political support or commitment and ii) their expectations of and interest in its outcome.

To create a sense of teamwork among people who previously did not even know each other, each with their own speciality, is a very difficult and complex task. The project leader needs to build a committed project group, achieve the full benefits, both personally and to the department, by cross-functional collaboration. Departmental teamwork (Breiner et al., 1990, p. 9) incorporates three dimensions in the project leader's role namely i) management of stakeholders in the project ii) management of the project life cycle and iii) management of the performance of individuals.

Knutson (2001, p. 431) refers to the project-management office as an autonomous group that provides project-management support services. This group should be viewed as a service to be shared by all functions within the department. The job of this group is focussed on the discipline of project management.

According to Crawford (2002, p. 10) the project-management office makes the lives of project team members easier by supporting the team in the areas of, among others, scheduling, status reporting, project tool operation and training. Some of the key items of support provided by the project-management office include consulting and mentoring of current staff, developing and promulgating methodologies and standards relating to project management, and servicing as the central source for help in planning and managing efforts.

The project-management office facilitates the improvement in project-management maturity by being the focal point for consistent application of processes and methodologies. Without a project-management office it might be possible that the project-management efforts of the department are not consistent and are not focussed on a common vision. The project- management office is the proverbial glue that holds the projectmanagement efforts of the department together.

\section{THE HUMAN RESOURCE EFFICIENCY MODEL}

\section{Data}

A survey was developed in order to capture the required data. The survey was designed for simplicity of response in order to capture the greatest level of accuracy in the shortest possible time. The answers were divided into interval ranges as opposed to point estimators. This greatly simplified the interview process and reduced subjective interpretation to a bare minimum. The survey was divided into dispersed or scattered groups, focussing independently on each of the categories that make up the model for human resource project management efficiency. Each category was laid out in order to create a degree of continuity from statement to statement. The survey contained seventeen statements that were divided into three different categories (annexure A). The statements were taken from project management literature and interviews with managers, project managers and project co-ordinators within the DPE. The survey was sent to thirty five existing managers, project managers and project co-ordinators within the DPE, chosen from a list of current project users. Respondents were chosen in such a manner that a representative sample group for each of the following six functions were included in the project. The different functions of respondents were divided into the following six areas, namely a) functional manager/departmental head b) part-time project co-ordinator c) full-time project coordinator d) part-time project manager e) full-time project manager and f) project team member. The respondents were requested to indicate on a scale of 1-5 the importance of each statement in attaining a high level of efficiency in project management (annexure A). The average values of the statements per category and per respondent were recorded in the different data series.

The survey was also designed to facilitate the conversion of responses into data points in order to transfer them easily into a database and then interpret them with the assistance of a statistical package called SPSS version 11 for windows. In terms of the SPSS package the data results were tested by employing the Kaiser-Meyer-Olkin measure of sampling adequacy and the establishment of a covariance matrix in which a reliability analysis can be performed.

The univariate properties of the data were also tested. The ADF test, Phillips-Perron test and correlogram tests were used to test for stationarity and the level of integration of each of the variables in the regression. The tests were performed on the data in their logarithmic form. From the ADF- Phillips-Perron tests it has been determined that all the variables were integrated of the order 1 .

\section{Model}

A power function was specified in order to determine the average elasticities of the three efficiency categories (independent variables). The average elasticities would indicate the relative magnitude of the impact of a specific category on the efficiency of project management.

$$
\mathrm{U}=\mathrm{a}\left(\mathrm{Cat}_{1} \mathrm{~b}\right)\left(\mathrm{Cat}_{2}{ }^{\mathrm{c}}\right)\left(\mathrm{Cat}_{3}{ }^{\mathrm{d}}\right) \text {....equation } 1
$$

(where $\mathrm{U}$ is the efficiency variable, $\mathrm{Cat}_{1}$ represents appropriate project-management methodology, $\mathrm{Cat}_{2}$ represents effective learning and authority structure and $\mathrm{Cat}_{3}$ represents adequacy of human resources).

The power function was transformed into a double log equation which is linear in logarithms and was then run on the log of the variables. 
$\ln \mathrm{U}=\ln \mathrm{a}+\mathrm{b} \ln \mathrm{Cat}_{1}+\mathrm{c} \ln \mathrm{Cat}_{2}+\mathrm{d} \ln \mathrm{Cat}_{3} \ldots$ equation 2

The estimation results were:

$$
\begin{gathered}
\mathrm{U}=12,25\left(\mathrm{Cat}_{1}^{4,74}\right)\left(\mathrm{Cat}_{2}^{8,44}\right)\left(\mathrm{Cat}_{3}{ }^{7,11}\right) \\
(3,87)(4,88)(4,68)(3.97) \ldots \text { equation } 3
\end{gathered}
$$

Number of observations: 35

$\mathbf{R}^{2}: 0.91$

F-statistic: 188.24

D-W: 3.38

The good overall explanatory power of the entire regression is indicated by high $\mathrm{R}^{2}$ and F-statistic values and all the t-statistics of estimated parameters clearly exhibits explanatory power.

Econometric tests were conducted to determine any traces of autocorrelation and heteroscadacity. The D-W statistic exceeds $\mathrm{d}_{\mathrm{u}}$ clearly indicating no autocorrelation. The $\mathrm{ARCH}$ test conducted indicates no heteroscedasticity present in the error terms, therefore the estimators are asymptotically efficient. The error terms were not serially correlated and it can be stated that all the explanatory variables have been included in the equation.

The positive signs of all the estimated average elasticities indicate a positive relation between the three different categories of project management and the attainment of project management efficiency. From the estimated results it is clear that effective learning and authority structures (an elasticity coefficient of 8,44 ) can be ranked as the most important human resource driving force followed by the adequacy of human resources needed to execute projects (an elasticity coefficient of 7,11 ) and only then appropriate project management methodology (an elasticity coefficient of 4,74$)$.

\section{MANAGEMENT IMPLICATIONS}

The organisation needs to foster a learning culture in which the participants in the different projects are able to learn from mistakes made in other similar projects and also develop natural competitive skills in order to improve performance. This learning culture can only be effective in an environment where bureaucratic systems are kept to a bare minimum.

Project managers must also be awarded the necessary authority structures to execute projects, to have full control over their projects and be held responsible for the successful execution of their projects.

The organisation should make sure that sufficiently skilled people in project management practices are employed, that they have sufficient problem-solving skills and that they are able to act as competent project leaders. Project managers should be allowed to take initiative and to be rewarded in accordance with their performance.

Lastly, much more than just training will be required to acculturate the organisation into being supportive of project management. Several mechanisms will be required, in conjunction with the suggested training to address the outcomes highlighted by the questionnaire. These are i) implementation of proper change-management ii) relevant process changes iii) appropriate leadership to bring about change iv) culture changes to accept project-management methodology within the DPE and v) departmental changes to accommodate project management into the DPE structure.

\section{CONCLUSION}

The paper has dealt with the econometric modelling of the important human resource drivers for project management best practices. The results of the efficiency model will impact on the manner in which the human resource priorities for optimal project management are ranked and finally addressed and implemented.

\section{REFERENCES}

Archibald, R.D. 2003. Managing High-Technology Programmes and Projects. $3^{\text {rd }}$ edition. Hoboken : John Wiley \& Sons, Inc.

Breiner, W., Geddes, M \& Hastings, C. 1990. Project Leadership. New York : Van Nostrand Reinhold.

Crawford, J.K. 2002. Project Management Maturity Model. New York : Marcel Dekker AG.

Frame, J.D. 2002. The New Project Management. $2^{\text {nd }}$ edition. San Francisco : Jossey-Bass, Inc.

Gray, C.F. \& Laron, E.W. 2003. Project Management: The Managerial Process. New York : Mc'Graw-Hill.

Kerzner, H. 2001. Strategic Planning for Project Management using a Project Management Maturity Model. New York: John Wiley $\&$ Sons, Inc.

Knutson, J. 2001. Succeeding in Project-Driven Organisations. New York : John Wiley \& Sons, Inc. 


\section{Annexure A}

Using the following 5 point scale, indicate in a range between 1 and 5 which of the following best describes your attitudes towards the listed statements in terms of project management.

\begin{tabular}{|l|l|l|l|l|}
\hline Not important at all & Limited contribution & Neutral & Important \\
\hline 1 & 2 & 3 & 4 & Very important \\
\hline
\end{tabular}

The different categories and statements are listed in the following set of tables.

Category 1: Appropriate project-management methodology.

This category describes the degree to which the department follows a standardised and formal methodology of project management with appropriate systems and processes.

\section{Statements}

1. Projects across the department are measured on a standarised basis against performance achievement.

2. Projects across the department are measured on a standarised basis against time.

3. Projects across the department are measured on a standarised basis against budget.

4. Standardised project management methodology supports the successful completion of projects within the department.

5. Project managers execute their projects in a disciplined and structured manner.

Category 2: Effective learning and authority structure.

This category describes the extent to which there are effective ways of organising project teams, learning from previous project mistakes, assigning project responsibilities, and delegating authority to make decisions.

\section{Statements}

6. Project managers do have the necessary authority to execute their projects.

7. Project managers are able to learn from mistakes made on other, similar projects.

8. Natural competitiveness of project managers is used to improve performance.

9. Project managers have full control of their projects.

10. Project managers are held responsible for their project management success.

11. Project managers can execute their projects effectively due to minimum bureaucratic systems in the department.

Category 3: Adequacy of human resources.

This category describes the extent to which people assigned to projects are generally competent in their line of specialisation and display a sufficient commitment to delivering quality work.

\section{Statements}

12. Projects managers are rewarded in accordance with their performance.

13. The department allows for project managers to take initiative.

14. Project managers are trained sufficiently to be competent project leaders.

15. People who train project managers in the department are sufficiently skilled in project management related skils.

16. Project team members have adequate project management related skills.

17. Project managers have sufficient problem-solving abilities. 